\title{
Do discurso prático à prática discursiva: a mobilidade urbana e seu contexto sociopolítico. Contradições e lacunas entre a elaboração e execução do planejamento das políticas de transporte nas cidades brasileiras - o caso da Região Metropolitana do Recife (RMR)
}

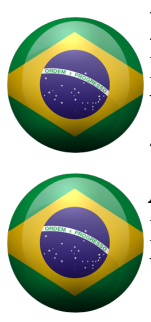

\section{Nivaldo Gerôncio da Silva Filho}

Professor de EAD/Sead/UFSCar, Dep. Eng. Civil. Doutor [PPG Engenharia Urbana / UFSCar]. Mestre em Urbanismo [PPG Desenvolvimento Urbano / UFPE]. Cientista Social-Sociólogo. São Carlos [SP] Brasil. $<$ nivaldo.geroncio.filho@gmail.com>

\section{Archimedes Azevedo Raia Junior}

Professor Associado do Departamento de Engenharia Civil [PPG Engenharia Urbana / UFSCar], Universidade Federal de São Carlos. São Carlos [SP] Brasil. <raiajunior@gmail.com>

\section{Resumo}

Em pouco mais de seis décadas, o debate em torno das ideias que agregam-se ao conceito da mobilidade urbana mesmo que não associadas diretamente ao termo, têm adquirido uma complexidade bastante acentuada e ao mesmo tempo contraditória, dada a multiplicidade de variáveis que nela passa a interferir, tornando-a passível de uma discussão que vai muito além do campo teórico. Na atualidade, o ângulo de discussão do tema direciona-se a dois aspectos inerentes a tais ideias: I) aquele concernente à relevância que é intrínseca ao espaço urbano que, por sua vez, caracteriza-se como um campo de discussão propício na fomentação do conceito; e II) aquele relativo à amplitude que, relaciona-se ao viés histórico a partir do momento em que o termo ganha ênfase; ao viés econômico no que se refere à produção interna do país; ao viés ambiental principalmente a partir de grandes conferências mundiais sobre o meio ambiente; ao viés social no atendimento inclusivo e essencial à população; e por fim um viés político, no tocante as tomadas de decisões. Assim, de modo geral o trabalho procura questionar as formas de planejamento urbano voltadas para os transportes nas últimas décadas. De modo específico o artigo lança foco nas contradições e lacunas entre a mobilidade urbana e as políticas públicas, ou seja, não nos parece tão claro, o seu processo de elaboração e execução, na medida em que as tais políticas não cumprem de forma efetiva seu papel, este fato traz um ônus muito elevado para os serviços públicos essenciais, tal como é o caso dos transportes. Procurar-se-á investigar essa problemática tomando como estudo de caso a Região Metropolitana do Recife (RMR), através de uma metodologia comparativa entre o discurso teórico e a prática evidenciada nos diversos modais de deslocamentos.

\section{Palavras-chave}

Mobilidade urbana. Políticas de transporte. Planejamento urbano.

The pratical speech to discursive practice: urban mobility and its sociopolitical context. Contradictions and gaps between the development and implementation planning of transport policies in Brazilian cities - the case of the Metropolitan Region of Recife (RMR)

\begin{abstract}
In just over six decades, the debate around the ideas that add to the concept of the same urban mobility not directly associated with the term, have acquired a very great complexity and at the same time contradictory, given the multiplicity of variables that it passes to interfere, making it the subject of a discussion that goes beyond the theoretical field. Currently, the angle of discussion of the topic directs to two aspects inherent to such ideas: I) that concerning the relevance that is intrinsic to the urban space which, in turn, is characterized as a field of discussion conducive in fostering the concept ; and II) one relative to the amplitude that is related to the historical bias from the moment in which the term gain focus; the economic bias in relation to domestic production of the country; environmental bias mainly from major world conferences on the environment; the social bias in the inclusive care and essential to the population; and finally a political bias, regarding decision making. Thus, generally the work seeks to question the ways of urban planning focused on transport in recent decades. Specifically the article takes focus on the contradictions and gaps between urban mobility and public policies, that is, it does not seem so clear, its process of preparation and implementation, to the extent that such policies do not fulfill effectively its paper, this fact brings a very high cost to essential public services, such as in the case of transport. Search it will investigate this issue using as a case study the Metropolitan Region of Recife (RMR), through a comparative approach between theoretical discourse and practice evident in the various modal shifts.
\end{abstract}

\section{Keywords}

Urban mobility. Transport policies. Urban planning. 


\section{Especificidades conceituais}

Apesar do amplo debate em função do conceito da mobilidade urbana, é possível observar que pouco se tem avançado no sentido de empreender um planejamento que seja de fato exitoso. Assim, a evidência da problemática urbana direciona-se e debruça-se sobre dois aspectos, sendo eles amplos e complexos.

No que se refere ao primeiro, destaca-se que:

- A abordagem na qual se insere o conceito de mobilidade, ligada à necessidade cada vez mais evidente de circulação urbana dentro de um espaço bastante disperso, devido aos diversos interesses, confere um alargamento da aplicação de seu termo. Cada vez mais é possível observar que toda a dinâmica da cidade trouxe consigo uma série de contrapontos principalmente nos deslocamentos, em outras palavras, pensar na necessidade de deslocamentos diários significa pensar numa teia complexa, na qual é extremamente importante considerar toda performance do sistema que compõe os diversos modos.

Quanto ao segundo, observa-se que:

- No caso brasileiro, o debate está associado diretamente à discussão relacionada ao contexto que se define a partir da década de 1950, porque a partir desse momento, observa-se o crescimento acentuado das capitais brasileiras, maior preocupação com a questão ambiental, a evidência acelerada do processo de segregação socioespacial e a falta de articulação nas tomadas de decisões para priorizar necessidades entre as esferas federal, estadual e municipal, constituindo, portanto, como premissas fundamentais de sustentação desse conceito.

Tomando como base o contexto mundial, cabe ressaltar que:

- Em 1950, a população mundial era de 2,5 bilhões, em 2000 cresceu para 6,0 bilhões e é estimado que em 2030 o número de habitantes do planeta chegue a 8 bilhões. Estes números que impressionam, significam uma demanda cada vez maior por transporte, seja para movimentar bens ou pessoas. Evidentemente, esta atividade irá gerar uma série de impactos no meio ambiente (Ribeiro, 2003).

O intenso crescimento experimentado pelo Brasil trouxe consequências bastante delicadas, as consequências de tal fato, incidiram sobretudo nas áreas urbanas. A década de 1950 foi um divisor nesse processo de crescimento, que, diga-se de passagem, não significou desenvolvimento como muito bem ressaltado por Dedecca; Trovão e Souza (2014), ao enfatizar que no pós-guerra (1945-1980), o Brasil se destacou entre os países em desenvolvimento por apresentar o maior dinamismo econômico. No entanto, sua virtuosidade econômica não se traduziu em resultados sociais positivos. Ao final do longo ciclo de crescimento, a consolidada sociedade urbana e industrial convivia com uma situação de elevada desigualdade socioeconômica, permeada por problemas sociais de toda ordem e com extenso nível de pobreza. Nesse contexto, devido ao intenso crescimento urbano no Brasil a partir da década de 1950, muitas cidades - e regiões metropolitanas (RM's) - passaram a apresentar sistemas de mobilidade de baixa qualidade e de alto custo, com impactos negativos na vida das pessoas, ou seja, nos custos sociais, econômicos e ambientais (IPEA, 2011a). Acrescente-se ainda, a falta de articulação entre as esferas governamentais que teve papel relevante no processo de estruturação das metrópoles brasileiras.

Assim, as condições efetivas de mobilidade por extrato social, dos consumos e das externalidades a elas associadas é fundamental para avaliar a qualidade da vida nas cidades no país e identificar ações de políticas públicas que possam reduzir os problemas urbanos de mobilidade, dando maior eficiência na movimentação de indivíduos e mercadorias e garantindo às pessoas o seu direito à cidade (IPEA, 2011b).

Nessa ótica, observa-se que a larga difusão do termo mobilidade urbana, fez surgir a preocupação com os fatores sociais, econômicos, políticos e, sobretudo ambientais, emergindo na necessidade 
de um novo conceito que pudesse associar de forma conjunta e pertinente os fatores citados. Assim sendo, na atualidade e, de modo amplo o conceito ficou definido como "um atributo que está associado à cidade" (Ministério das Cidades, 2006). Essa abordagem, que insere o conceito de mobilidade urbana como um termo que deve congregar os fatores sociais, econômicos e ambientais ligados às características que compõe o espaço, leva-nos a pensar a respeito de duas relações importantes para o entendimento do contexto em questão.

A primeira:

- Diz respeito ao adensamento urbano e a forma de estrutura que é dada à circulação de pessoas e de veículos no espaço metropolitano. Tal relação se caracteriza de forma complexa, na medida em que as cidades se dispersam e, os destinos tornam-se cada vez mais distantes entre si, inviabilizando o deslocamento a pé e gerando a necessidade do uso de equipamentos de transporte individual ou coletivo. Pinto (2010a, p.5) destaca que, "nesse sentido, desponta a necessidade de se compreender e enfrentar o padrão de urbanização dispersa, em curso no país, que torna proibitivos os custos de funcionamento dos serviços públicos". Assim ressalta-se que "ao longo de 30 anos, a ANTP vem tentando chamar a atenção para este problema. Para algumas cidades, as condições de circulação estão se tornando mais drásticas e concorre para um cenário ainda mais grave no tocante à mobilidade urbana" (Pires, 2008, p.6). Ainda nesse sentido, reforça-se que "o crescimento das cidades brasileiras passou a ser orientador por um modelo excludente, na medida em que esse modelo concentra riquezas das classes de maior poder aquisitivo e outras, abrigando população de baixa renda, em periferias desprovidas de infraestrutura e de serviços básicos" (Bicalho, 2010a, p.5).

A segunda:

- Trata-se da mobilidade urbana e as políticas públicas, ou seja, não nos parece tão claro que, exista uma coerência entre seu processo de elaboração e execução, na medida em que a formulação teórica de tais políticas não é coerente com a realidade prática, este fato traz um ônus muito elevado para os serviços públicos essenciais, tal como é o caso dos transportes. Bicalho (2010b, p. 6) salienta ainda, "o Brasil necessita de uma política nacional para mobilidade urbana que, a luz da Constituição de 1988, seja compatível com a descentralização político-administrativa ocorrida no país com a autonomia dos poderes e respeito as áreas próprias de atuação dos três níveis de governo". De acordo com Gomide (2003), "as políticas públicas para o setor de transporte são essências e, conferem aos cidadãos a condição de direitos fundamentais e universais e que estão expressas na Constituição". Nesse ponto, a própria constituição reforçar que "sem o acesso a esses serviços, as pessoas estarão seriamente limitadas para desenvolver suas capacidades, exercer seus direitos ou para equiparar oportunidades" (Constituição Federal, art.30 inciso V, 1988).

Com efeito, cabe ressaltar que o atendimento das necessidades que possa englobar os fatores sociais, econômicos e ambientais das pessoas requer seu deslocamento no espaço, que pode ser visto de forma complexa. Daí porque "a melhoria dos transportes são condições indispensáveis para promover cidades com qualidade de vida" (Pinto, 2010b, p.6). A autora destaca ainda que é necessário fomentar alguns requisitos básicos tais como: aperfeiçoamento da gestão do serviço; organização de redes integradas; desenvolvimento de fontes de energia renovável, prioridade aos meios de deslocamentos coletivos e não motorizados e; uso intenso de tecnologias para controle operacional e informações aos usuários. Assim, seguindo essa linha de raciocínio, com uma preocupação atual o Ministério das Cidades traçou alguns planos e metas para a mobilidade urbana, englobando o transporte como parte integrante do sistema. Entretanto, se as políticas públicas para este setor não forem aplicadas, todas as ações desenvolvidas ficarão limitadas ao contexto teórico. A Secretaria Nacional de Transporte e da Mobilidade Urbana [SEMOB] foi instituída no Ministério das Cidades com a finalidade de formular e implementar a política de mobilidade urbana sustentável, entendida como "a reunião das políticas de transporte e de circulação e integrada com a política de desenvolvimento urbano, com a finalidade de proporcionar o acesso amplo $e$ democrático ao espaço urbano, priorizando os modos de transporte coletivo e os não motorizados, de forma segura, socialmente inclusiva e sustentável". As atuais condições de mobilidade e dos serviços 
de transporte público no Brasil direcionam a atuação da SEMOB (2006) para três eixos estratégicos que agrupam as questões a serem enfrentadas:

1. Promover a cidadania e a inclusão social por meio da universalização do acesso aos serviços públicos de transporte coletivo e do aumento da mobilidade urbana;

2. Promover o aperfeiçoamento institucional, regulatório e da gestão no setor;

3. Coordenar ações para a integração das políticas da mobilidade e destas com as demais políticas de desenvolvimento urbano e de proteção ao meio ambiente.

Há algumas décadas, [...]

[...] de modo geral, a característica mais notável da mudança urbana éo rápido crescimento da periferia e a perda de população nas áreas do núcleo central. Mas não parece muito evidente que o declínio demográfico ou de atividades econômicas seja suficiente para diminuir os problemas de transporte no coração das cidades (Owen, 1971a, p. 26).

Gottdiener (1997) destaca as implicações sociais, políticas e econômicas, dentro do espaço urbano, e chama a atenção para a falta de um olhar mais eficiente por parte dos planejadores urbanos, nas diversas áreas. Em suma, ele aponta para a forma desarticulada no tratamento dos serviços básicos urbanos e evidencia as diferenças dos modos de vida urbano. De acordo com essa visão, as dinâmicas das funções urbanas, sobretudo dos transportes, fizeram surgir a necessidade da busca por novos espaços, onde se observou um crescimento intenso, porém não necessariamente estruturado.

Evidentemente, Gottdiener (1997) tem uma razão muito significativa quando ele afirma que existem muitos autores que tratam da questão dos deslocamentos dentro do espaço urbano, como uma forma simples, o que não é coerente. Dentro de uma perspectiva mais específica, para Oliven (1984a), a cidade deve ser encarada como uma variável dependente e complexa em si, considerando seus fatores econômicos, ambientais, políticos e sociais.

A distribuição do espaço para a prioridade de veículos e pedestres é desigual, isso pode parecer normal no que se refere às áreas mais distantes dos grandes centros para atender aos deslocamentos mais longos, mas a discussão aprofunda-se na medida em que mesmo em áreas centrais a prioridade de ordenamento entre o modo motorizado e não motorizado continua sendo significativa, com impactos direto no espaço e nos demais modos.

\section{A política, planos, metas e diretrizes nacionais, estaduais e municipais voltados à Mobilidade Urbana: o planejamento em foco}

Para compreender a problemática da mobilidade urbana na atualidade é indispensável analisar o contexto nacional e local que teve início a partir de década de 1950, com foco específico na relação entre o crescimento urbano e a elaboração de planos para os serviços básicos para as capitais, tal como é o caso dos transportes nos seus mais diversos modais, com a participação das três esferas no setor. Sendo assim, no contexto nacional até meados da década de 1960, a Política de Desenvolvimento Urbano como um todo e, em particular, a Política Federal de Transporte Urbano levadas a cabo no Brasil caracterizavam-se por aquilo que Francisconi e Souza (1976, p.16) chamam de "política de fato". Não se distinguindo de uma multiplicidade de iniciativas e ações desarticuladas aplicadas por diferentes setores do governo, sem diretrizes ou estratégias básicas de ação no meio urbano.

Santos Junior (2007, p. 293) ressalta, à primeira vista, parece possível afirmar que se desenvolve no Brasil uma nova cultura de planejamento decorrentes tanto da incorporação dos instrumentos inscritos no Estatuto da Cidade quanto da participação de atores sociais com presença na cena pública. Araújo (2003, p.61) condiciona o planejamento o fracasso do planejamento as soluções emergências, que cada vez mais se mostram ineficientes, e afirmar que, no atual cenário, poucas atitudes tomadas pelos planejadores urbanos de modo geral, tem surtido algum efeito na gestão das atividades e principalmente na qualidade de vida da população. 
Villaça (1999) é mais crítico e afirma de forma clara que no campo do planejamento, o planos diretores são incapazes de atender as necessidades mínimas, ainda segundo ele, seria preciso fazer uma profunda reflexão em suas bases. Já para Maricato (2012), o modelo urbano capitalista que ganhou força a partir da década de 1990 é em parte responsável pela exclusão de uma parcela significativa da população, ainda para a autora, a mobilidade urbana foi afetada de forma impactante na medida em que não houve de fato uma relação dos modais de transporte, sobretudo o transporte coletivo com o uso e ocupação do solo.

Ainda nessa perspectiva mais que planos, projetos devem ser elaborados a longo prazo. Para Vasconcellos e Mendonça (2010a, p.78), a elaboração das políticas de transporte no tocante a participação federal no setor de mobilidade urbana até a primeira metade da década de 1970 era praticamente nula. "Sendo as atribuições e ações no setor de transporte público e trânsito de competência exclusiva da esfera municipal e estadual" (Vasconcellos \& Mendonça, 2010b, p.78). Contudo, pode dizer que no período compreendido entre 1960 a 1980 observa-se uma ação coesa, embora com bastantes incoerências de construção de uma política nacional de desenvolvimento urbano, com uma ativa participação federal sobre o transporte das cidades brasileiras.

Particularmente no setor de transporte urbano, esse período possui como marco inicial a criação de algumas instituições que se tornariam as referências técnicas e financeiras do setor. A primeira dessas instituições foi o Grupo Executivo de Integração da Política de Transportes (GEIPOT), cuja criação em 1965 teria colocado pela primeira vez na história o transporte urbano. Nesse período, destacam-se também a proposição da Lei no 6.261/1975, que criava toda uma nova concepção institucional para o setor com a criação do Sistema Nacional de Transporte Urbano (SNTU), da Empresa Brasileira de Transporte Urbano (EBTU) e de um fundo setorial, o Fundo de Desenvolvimento dos Transportes Urbanos (FDTU), todos eles vinculados ao Ministério dos Transportes.

Ainda na década de 1970 a criação da Rede ferroviária federal (RFFSA), da Divisão Especial de Subúrbios do Grande Rio e da Divisão Especial de Subúrbios de São Paulo, e que anos mais tarde, em 1984, daria origem a criação da CBTU. Essas instituições constituiriam o núcleo duro da Política Federal de Transporte Urbano. E, durante esse período, entre meados das décadas de 1960 e 1980, esta se caracterizava por atuar fundamentalmente com programas de financiamento e de assessoramento técnico prestado pela GEIPOT e pela EBTU aos municípios sobre questões de planejamento e gerenciamento de seus sistemas de transporte urbano.

Um terceiro período a se destacar no histórico da Política Federal de Transportes Urbanos, e na Política Federal de Desenvolvimento Urbano como um todo, localiza-se entre meados da década de 1980 e fins da de 1990, período marcado por um contexto de crise econômica internacional, observando-se um claro processo de desmobilização das políticas setoriais urbanas, com sensível instabilidade institucional para a política urbana e redução de seus recursos disponíveis (Souza, 1992; Lima Neto, 2001; Gomide, 2008).

Entre 1985 e 1995, a responsabilidade sobre o tema urbano passou caoticamente por mais de cinco ministérios. Com a política de redução do Estado, por exemplo, foram encerradas as atividades de instituições chave como o BNH em 1986 e o Conselho Nacional de Desenvolvimento Urbano (CNDU) em 1990. A EBTU perde seus recursos vinculados a partir de 1982, tendo de recorrer à captação de recursos externos, sobretudo do Banco Mundial (BIRD), até sua extinção em 1989 pelo Decreto no 97.455/1989 (IPEA, 2011b).

No que diz respeito ao contexto local, ou seja, no âmbito do Estado e dos respectivos municípios, da RMR a importância incide no fato de a RMR tem características que compõem uma grande metrópole brasileira que enfrenta na atualidade problemas de mobilidade urbana, de âmbito geral, ou seja, nos diversos modais motorizados e não motorizados.

No momento que novos investimentos começam a ser implantados, a exemplo de portos e estaleiros, cresce a demanda por estruturas e serviços diretamente ligados à circulação urbana. Visto dessa forma, há uma tendência ao agravamento dos problemas ligados à infraestrutura. Na Figura 1, estão representados todos os municípios que compõem a RMR, com o respectivo o número de habitantes e suas áreas. 
Em 1979, foi aprovado o Plano Diretor de Desenvolvimento do Recife (PDR). A Lei de $n^{\circ}$. 14110 estabelece em seu Artigo $2^{\circ}$ os objetivos do Plano:

- Ordenar o crescimento urbano da cidade, através da distribuição equilibrada dos assentamentos e da garantia de reserva de espaços, destinados ao desenvolvimento adequado das diferentes atividades;

- Ampliar a produção dos serviços básicos, especialmente saúde, educação, abastecimento, assistência social e transporte de massa, visando a aperfeiçoar as condições de convivência urbana. Na prática, o Plano foi aplicado só parcialmente, o que resultou numa desestruturação para a cidade.

Na RMR, o cenário atual da mobilidade urbana pode ser evidenciado de forma preocupante. No final de maio de 2010, o Recife atingiu uma marca impressionante: 500 mil veículos nas ruas. Esse número reflete a sensação de colapso urbano e tende a agravar-se de forma exponencial. Em alguns corredores de trânsito, a velocidade média ficou em inaceitáveis $8,7 \mathrm{~km} / \mathrm{h}$. São 100 novos carros por dia, no Recife que é a capital do Nordeste, apresentando a maior relação carro/população ${ }^{1}$.

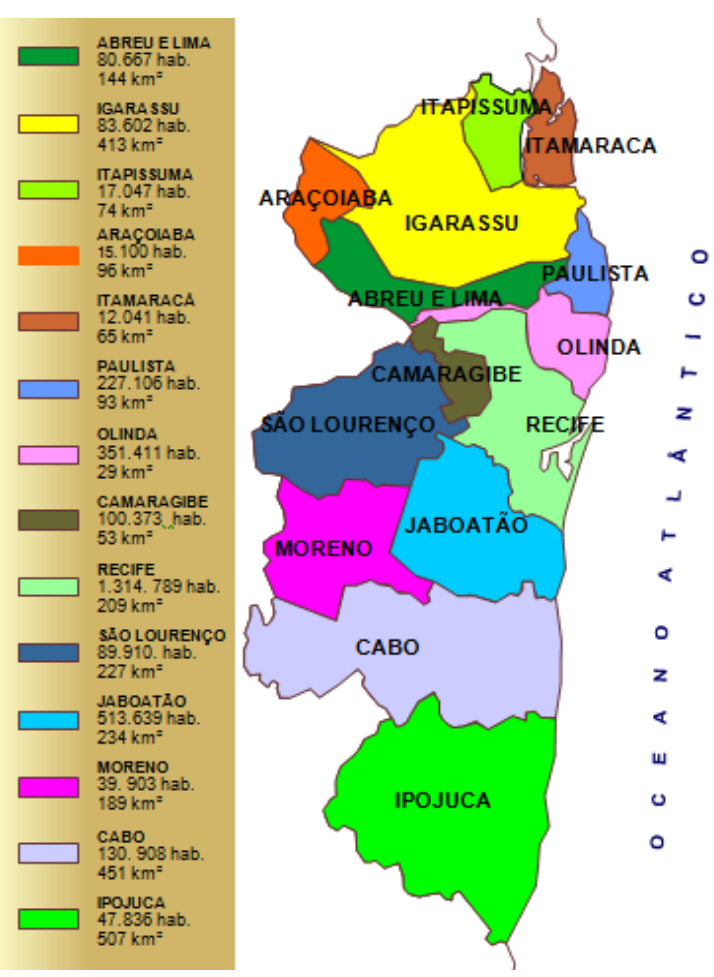

Figura 1. Mapa da Região Metropolitana de Recife. Fonte: os autores (2016), com base nos dados geopolíticos da Prefeitura da Cidade do Recife.

A Figura 2 ilustra o aumento significativo do transporte privado por veículos em três décadas e evidencia a falta de políticas públicas para este setor. De acordo com Lima Neto (2010a), o Recife tem algumas desvantagens em relação a outras capitais como, por exemplo, São Paulo, em virtude de que, "A nossa frota é menor, mas o nosso sistema viário é pior e defasado".

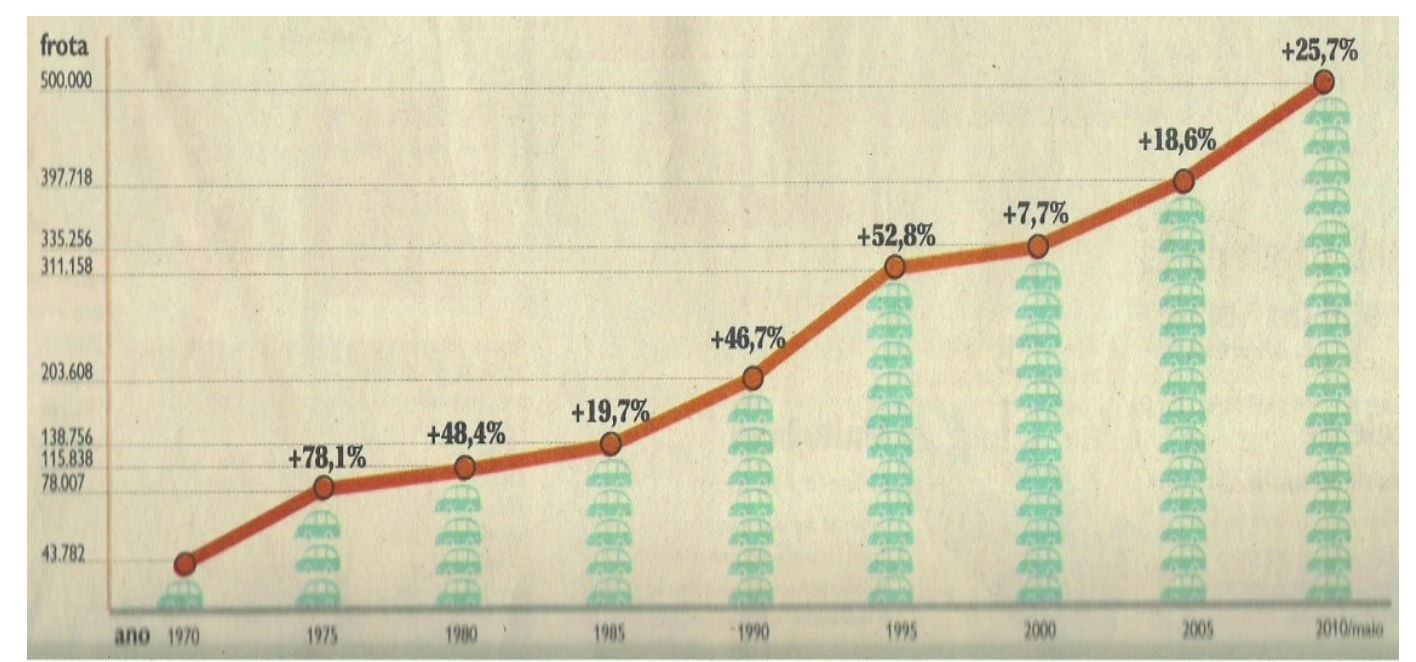

Figura 2. Percentagem do aumento da frota de veículos. Fonte: Jornal Diário de Pernambuco (2010).

De acordo com Lima Neto (2010b) e Santos (1994a), a falta de flexibilidade e de mobilidade no funcionamento da estrutura faz com que a cidade seja impedida de exercer plenamente o seu comando sobre a região que a compreende. Nesse ponto, "a mobilidade urbana pode ser considerada um conjunto estruturado de modos, redes e infraestrutura, constituindo um sistema complexo" (Macário, 2003). Para a autora, um fator determinante para o desempenho de todo o sistema é a forma como suas partes se relacionam. Este fato tem um fundamento lógico e pode

\footnotetext{
${ }^{1}$ Jornal Diário de Pernambuco. Série especial sobre Mobilidade e Transporte Público, junho de 2010.
} 
ser provado, na medida em que, na RMR, os deslocamentos há algum tempo já não correspondem às expectativas e necessidades de seus habitantes.

As Figuras 3 e 4 ilustram que a eficiência da mobilidade urbana na atualidade é complexa, observase que independe do modal escolhido, os deslocamentos como um todo não consegue atender à demanda cada vez mais dispersa. Em outro modo coletivo, que é o metrô, uma rápida avaliação feita pelo Plano Diretor de Transporte Urbano da Região Metropolitana do Recife (PDTU) constatou que a malha metroviária precisaria crescer mais de $35 \mathrm{~km}$ até 2020.

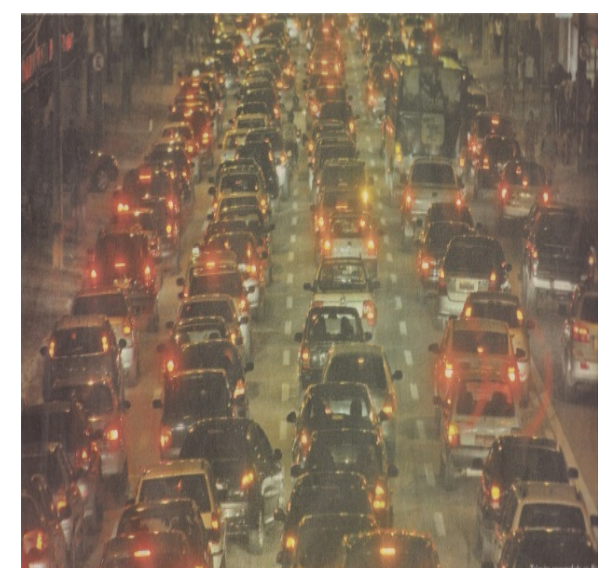

Figura 3. Av. Antonio de Góes, Bairro de Pina, Recife. Fonte: Jornal Diário de Pernambuco, 2010.

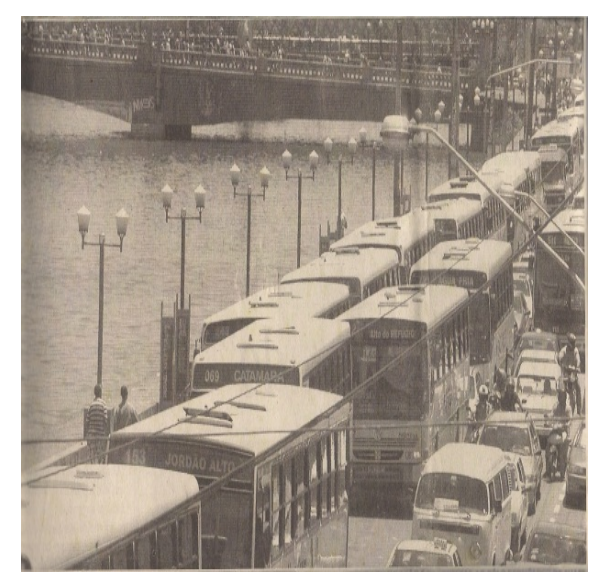

Figura 4. Rua da Aurora, centro do Recife. Fonte: Jornal Diário de Pernambuco, 2008.

No tocante aos meios de transportes não motorizados, em sua forma efetiva e socialmente inclusiva, a cidade do Recife vive um contraste significativo porque não consegue atender os deslocamentos essenciais. Nessa lógica, o pedestre e o ciclista deveriam ter prioridades, o que na prática não ocorre, tendo em vista a precariedade para esses modais, devido à falta de infraestrutura adequada. Dentro desse contexto em que se encontra a mobilidade, o deslocamento a pé é pensado como uma das grandes saídas para os diversos destinos. Um relatório elaborado recentemente comprovou que "em municípios acima de 60 mil habitantes, esse modo representa 37,5 \% dos deslocamentos totais" (ANTP, 2011). Contudo, o que se observa é a falta de infraestrutura para essa modalidade de transporte. "Grosso modo, muito se tem feito para aprimorar a acessibilidade dos pedestres, através de melhorias em passeios e calçadas, entretanto o que se tem de fato são problemas antigos para novos conceitos" (Silva Filho 2010a, p.80). Na contramão de um conceito que busque a sustentabilidade, o que se observa são obstáculos que vai da questão da elaboração até a conservação. A questão torna-se mais grave quando se trata de crianças, idosos e cadeirantes.

Silva Filho (2010b, p. 80) ressalta ainda que "a dinâmica dos deslocamentos dentro do espaço urbano foi significativamente alterada, acarretando a perda da mobilidade urbana das pessoas". Deste modo, numa visão mais ampla, as calçadas devem proporcionar acesso e mobilidade a todos os pedestres, haja vista que a sua estrutura afeta diretamente o deslocamento do pedestre, independentemente das suas condições físicas.

O planejamento para os pedestres não tem sido priorizado em relação ao planejamento dos veículos. A prioridade em atender à rapidez e à fluidez do tráfego de veículos tem resultado na gradual segregação de pedestres (Gondim, 2001).

As Figuras 5 e 6 evidenciam o que ocorre no centro do Recife e o contraste com o conceito de Mobilidade Urbana Sustentável. A calçada ou passeio público é um dos componentes básicos de uma via e tem como principal função, garantir condições adequadas de circulação para os pedestres. De forma, que sua utilização será determinada pelas suas condições. Segundo a Norma Técnica ABNT 9050-04 calçadas, passeios e vias exclusivas de pedestres devem incorporar faixa livre com largura mínima recomendável de $1,50 \mathrm{~m}$, sendo o mínimo admissível de $1,20 \mathrm{~m}$. Nenhuma calçada dos municípios deverá ter largura de passeio inferior a 1,20 m. 


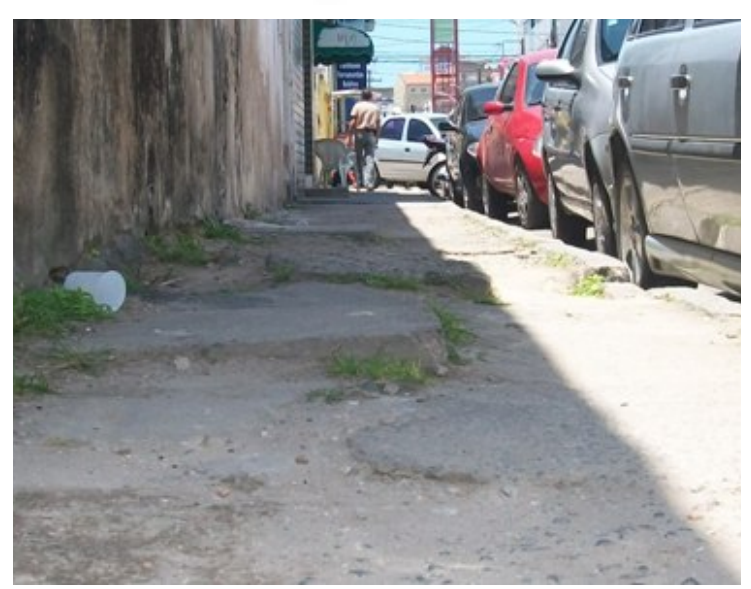

Figura 5. Rua Velha, centro do Recife.

Fonte: os autores, 2012.

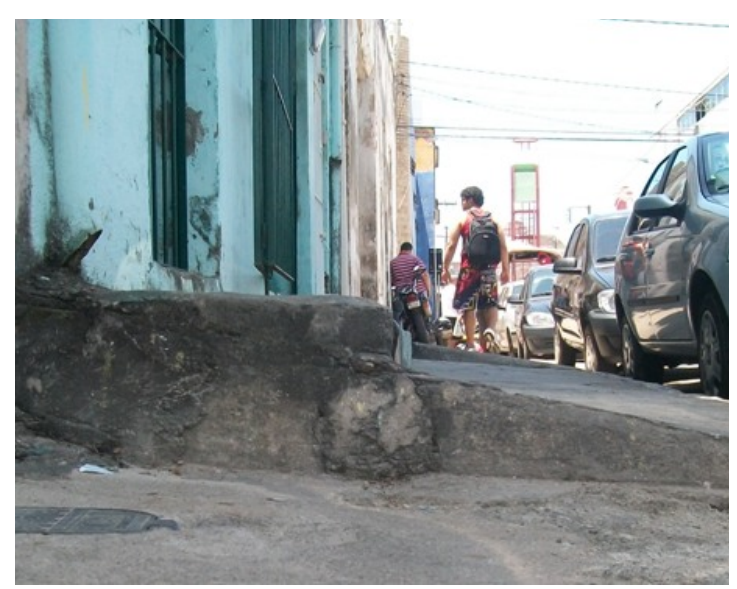

Figura 6. Rua da Glória, centro do Recife.

Fonte: os autores, 2012.

Em relação ainda a visão dos deslocamentos não motorizados, e em comparação com uma outra cidade do Nordeste a exemplo de Aracaju, a cidade do Recife apresenta um déficit muito significativo no tocante às ciclovias, aos passeios e calçadas, ou seja, seguindo a tendência da priorização do privado sobre o público e do motorizado sobre o não motorizado.

\section{Reiterando esse contexto, Câmara, Santos, e Braga (2000) destacam que [...]}

[...] algumas das varias vantagens dos deslocamentos são seu baixo custo, rapidez, confiabilidade e autonomia, no entanto o conflito entre o modal motorizado e não motorizado impõe uma serie de riscos (p. 113).

No bojo da discussão, fica evidente que as estratégias de planejamento urbano para atender o crescimento das cidades são tratadas de maneira equivocada, ou seja, tratadas de forma separada da questão da circulação. 0 conceito de mobilidade urbana sustenta que as políticas públicas de mobilidade (transporte, trânsito e de uso e ocupação do solo) devem ser elaboradas de maneira conjunta e harmoniosa.

De acordo com Vasconcellos (2000a), "no caso brasileiro, a forma de planejamento desenvolvida nos últimos anos foi equivocada porque não deu a devida atenção ao planejamento dos transportes e o planejamento da circulação". Assim, o autor define que "as três técnicas de intervenção estão intimamente ligadas na medida em que as decisões de uma podem afetar as demais". Desse modo, é possível observar no esquema apresentado na Figura 7, o padrão do modelo tradicional tomado pelos planejadores, e o modelo que seria mais bem adaptado ao caso brasileiro.

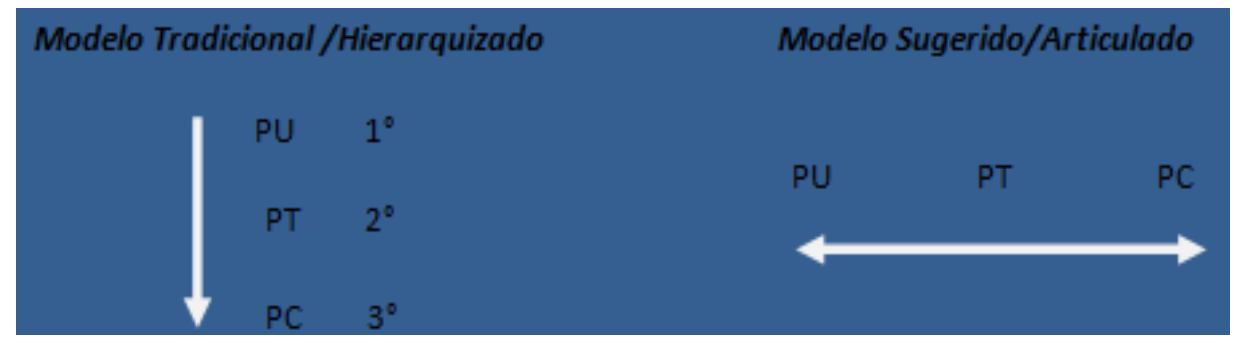

Figura 7. Modelos de planejamentos. Fonte: os autores, 2012, com base na argumentação de Vasconcellos, 2000, sendo: (PU) Planejamento Urbano; (PT) Planejamento dos Transportes; (PC) Planejamento da Circulação.

Com base neste esquema, a visão dos planejadores, ou seja, o modelo tradicional não deveria hierarquizar as técnicas de intervenções, o que na visão de Vasconcellos (2000) é inadequado, como enfatizado no modelo tradicional, mas sim tratá-las de forma linear, evitando a distribuição de um espaço escasso com interesses conflitantes.

De acordo com esse modelo, o problema da mobilidade urbana pode ser considerado fruto da implementação das políticas, ou seja, das falhas e lacunas entre o momento da elaboração até a execução. Sendo assim, tal modelo não consegue equacionar as responsabilidades das esferas federais, estaduais e municipais. 
A política de mobilidade tem por função proporcionar o acesso amplo e democrático ao espaço urbano, o acesso pode ser - e atualmente tem sido - proporcionado de forma excludente, que impacta gravemente sobre o espaço. Daí a necessidade de qualificar a mobilidade, repensando o objetivo de sustentabilidade (Ministério das Cidades, 2006).

A falta de um planejamento articulado resultou em impactos relevantes, para a sociedade como um todo, que segundo Bicalho (2010c) [...]

[...] a reversão ou minimização dos impactos desse modelo exigem que os municípios tenham controle efetivo sobre o uso e ocupação do solo e com o direcionamento mais rígido, sobretudo para os modos motorizados (Bicalho, 2010c).

\section{Resultados e discussões}

Os problemas relacionados à mobilidade nos centros urbanos afetam diretamente a qualidade de vida da população, com as externalidades negativas geradas na produção do transporte e, também, o desempenho socioeconômico das atividades urbanas. Dentro dessa perspectiva é possível afirmar que os deslocamentos das pessoas são meios para o desenvolvimento de praticamente todas as atividades humanas. Neste contexto, evidencia-se que a conformação espacial das cidades e, com ela, a localização das atividades de moradia, de trabalho, de educação, de laser entre outras, determinam a necessidade e a configuração dos deslocamentos, orientando a forma como eles estruturam-se.

De maneira mais incisiva, observar-se que os problemas urbanos na contemporaneidade, sobretudo os problemas da mobilidade, são processos que adquirem cada vez mais um viés cíclico, onde de forma geral remediar, ou seja, adaptar situações dentro do espaço vem se evidenciando como paliativo, porém os resultados obtidos são pouco eficientes. Segundo estudos do IPEA (2011d), mais do que isso, sistemas de circulação ineficientes pioram as desigualdades socioespaciais e pressionam as frágeis condições de equilíbrio ambiental no espaço urbano, o que demanda, por parte dos governantes, a adoção de políticas públicas alinhadas com o objetivo maior de alcançar uma mobilidade urbana sustentável, do ponto de vista econômico, social e ambiental.

Na prática, o que se questiona é a ação do Estado no papel das políticas públicas, pois os dados já expostos apontam para resultados negativos e lançam a indagação sobre a responsabilidade dos governos federal, estadual e municipal, no que diz respeito a um serviço público básico nesta área. A respeito ainda da responsabilidade das três esferas, Oliveira (2010) destaca que "o governo no Brasil é ausente, a ausência do Estado comprova os problemas da mobilidade urbana na RMR, seja na esfera municipal, seja na esfera estadual".

Os problemas atuais da mobilidade urbana perpassam as fronteiras sociais, daí porque Maia (2010) destaca que [...]

[...] nos últimos dez anos ocorreu uma "explosão da mobilidade", ou seja, uma "imobilidade" das metrópoles, a mobilidade se comporta de forma distinta para diferentes classes sociais: quanto mais alta, maior será o índice do uso do transporte privado. A carência de transporte público reforça a exclusão da população pobre e incentiva as viagens de automóveis de quem o possui, trocando viagens curtas a pé e de bicicleta por locomoções de carro Maia (2010).

No que se refere aos deslocamentos, Santos (1994b, p. 72) destaca: "isto se deve ao fato de que as grandes cidades são os centros mais dinâmicos da economia brasileira, nos quais suas contradições podem mais vivamente ser vistas e sentidas". Em concordância com este autor e reforçando o posicionamento de Maia, verifica-se que os padrões de mobilidade atual independem das classes sociais, visto que já atingimos um grau muito significativo de complexidade.

Trata-se, portanto, de uma problemática coletiva à qual as políticas públicas de transporte e os sistemas de circulação não conseguiram atender, à altura dos problemas de ordem infraestrutural. No contexto geral, a preocupação incide no fato de que [...] 
[...] o custo da construção de equipamentos urbanos básicos tem sido elevado com relação à maioria das receitas orçamentárias, nos países subdesenvolvidos, e continuará a sê-lo num futuro previsível (Haefele, 1973, p. 53).

Ressaltando essa ideia, Ferraz e Torres (2004, p.363) salientam que "é necessário contemplar no planejamento das cidades dois importantes aspectos que afetam diretamente a qualidade de vida da população: a acessibilidade e a mobilidade". Portanto, concretizando o contexto ora colocado, e ainda de acordo com Vasconcellos (2000b), observa-se que hoje a mobilidade é uma das questões centrais das cidades brasileiras, sobretudo da RMR onde deve ser enfrentada de forma articulada, para se obter soluções práticas.

Com base no contexto, a política e os planos voltados ao transporte devem orientar-se por objetivos e metas claras, ou seja, que possa reorientar ações concretas de forma coordenada e bem definida, através da tomada de decisão entre as três instâncias. Permitindo assim, investimentos que permitam de fato o desenvolvimento socioeconômico e possibilitando uma mobilidade que na prática seja eficiente. Recentemente, em 3 de janeiro do corrente ano, foi sancionada a nova Política Nacional de Mobilidade Urbana (PNMU) que entrará em vigor no prazo de 100 dias.

A Lei $12.587 / 2012$, que institui a PNMU, estabelece princípios, diretrizes e instrumentos para que os municípios possam planejar um sistema de transporte coletivo capaz de atender à população e contribuir para o desenvolvimento urbano sustentável. Nesse sentido, a lei incentiva a priorização do transporte coletivo, público e não motorizado, em vez do individual, particular e motorizado. Assim, determina, por exemplo, diversos mecanismos para garantir a oferta de gratuidades e a manutenção de passagens acessíveis nos meios de transporte coletivo.

Desse modo, as diretrizes da PNMU não poderão ser diretamente impostas aos municípios, já que estes têm competência para definir as regras do transporte urbano local. 0 governo federal poderá, no entanto, condicionar o repasse de verbas para projetos municipais de transporte à elaboração de planos baseados na PNMU.

Contudo, a presidente Dilma Rousseff vetou dispositivo que condicionava a concessão de benefícios tarifários à previsão em lei da origem dos recursos para seu custeio. Também rejeitou a possibilidade de estabelecimento de incentivos financeiros e fiscais para implementação das diretrizes da PNMU (Brasil, Secretaria de Imprensa da República, 2012).

\section{Considerações finais}

As ideias aqui colocadas, não objetivam encerrar a discussão, pelo contrário, buscam provocar ainda mais o posicionamento por parte daqueles que se interessam de alguma forma pelo tema. Contudo, observa-se que o ângulo da discussão da mobilidade é muito divergente, no que diz respeito à atual abordagem feita sobre a análise das políticas públicas, inclusive por especialistas no assunto. Assim, dentro dos contornos do debate sobre as teorias aplicadas à mobilidade, Vasconcellos (2000c) reforça esse raciocínio quando destaca que "as políticas de transporte e circulação constituem instrumentos imprescindíveis para a definição de vida na cidade". Para o autor, é fundamental fazer uma reavaliação dessas políticas e suas consequências para entender como as decisões, tomadas em décadas passadas, influenciaram na infraestrutura atual de circulação do ambiente urbano.

Quanto à importância dessa infraestrutura para a metrópole, a visão de Santos $(1982,1983$, 1993) alinha-se com a ideia de Vasconcellos, na medida em que afirma que a receptividade do espaço, possibilitada pela infraestrutura que traça no espaço vias de comunicação rápidas e integradoras, determina uma especialização funcional das cidades. Isso tem uma tem um rebatimento bastante expressivo na mobilidade urbana na medida em que essa mesma mobilidade pode ser determinada pela funcionalidade dos deslocamentos.

Para Owen (1971a), que traça uma visão dos transportes na necessidade da emergência urbana nos Estados Unidos, mas que se assemelha à nossa, "a imobilidade vem multiplicando as dificuldades e as frustrações da vida urbana, e em muitos lugares o crescimento da concentração 
humana parece ter ultrapassado o ponto de onde é fácil retornar". Owen (1971b) questiona ainda que a solução para melhoria dos transportes não é unânime e lança uma provocação enfática quando ressalta:

se o transporte coletivo não é a solução, quais as perspectivas que as modernas autopistas abrem para aliviar o meio urbano do congestionamento causado pala inadequação dos transportes? (Owen, 1971b).

Vale salientar que, quando Owen (1971c) trata da questão das autopistas, ele refere-se ao contexto norte-americano, que para nós pode ser traduzido em: privilegiar o transporte privado. Não é demais lembrar que, ainda nessa visão, o modelo brasileiro tem características similares ao modelo norte-americano.

Ao observarmos a dinâmica constituída pela mobilidade, através dos deslocamentos das pessoas dentro de um espaço como o da RMR, defrontamo-nos, pois, com os índices críticos que tendem ao agravamento, visto que os critérios aplicados à estrutura de circulação são meramente técnicos. Na verdade, a questão deveria ser enfocada no campo sociopolítico. No entanto, há autores que discordam dessa visão e seguem para uma análise sob a vertente histórica. Neto (2001) defende que, "no caso do setor de transportes, objeto de profunda reforma institucional e econômica nos últimos anos, as motivações históricas são mais agudas". Em concordância com a afirmação citada, observamos que a vertente histórica tem um respaldo significativo.

Não obstante verifica-se que, no tocante à infraestrutura de circulação da RMR, poucas intervenções foram realizadas, em comparação ao crescimento da população nas últimas seis décadas. $\mathrm{Na}$ visão de Brasileiro (2002), é imprescindível compreender a dinâmica dos transportes na RMR a partir de três pilares grandes elemento: o primeiro deles é a configuração física, o segundo é a configuração urbanística e o terceiro é a configuração político-institucional. Para Pina (2002), a problemática dos transportes está sobretudo no modelo de gestão que precisa ser aperfeiçoado.

De maneira geral, o processo de planejamento de transportes não tem apresentado a sensibilidade suficiente para resolver ou ao menos atenuar o conflito entre o que é planejado e a necessidade real dos cidadãos urbanos, principalmente os de menor renda. Além disso, embora seja frequente que as análises levem em conta aspectos ligados à acessibilidade, ou os ligados à mobilidade, isto em geral é feito de forma não associada (Raia, 2000).

Pode-se dizer que, as políticas de transportes, em sua grande maioria, não são planejadas adequadamente entre os órgãos federais e estaduais. Na maioria dos casos a elaboração e execução estão inseridas em Planos Diretores Municipais que não têm qualquer vinculação com políticas consistentes e de longo prazo. De modo que, há uma contradição entre a cidade ideal, ou seja, teorizada em políticas e planos versus a cidade real que se caracteriza no emergente agravamento dos deslocamentos. Acarretando lacunas na mobilidade urbana e consequentemente incoerência no sistema de circulação.

\section{Referências}

A cidade refém dos automóveis. (2010, junho, 6). Jornal Diário de Pernambuco. Caderno: vida urbana, C 1, 2, 3, 4. Recife, PE, Brasil.

A derrota coletiva na guerra por espaço. (2010, junho, 9). Jornal Diário de Pernambuco. Caderno: vida urbana, C4. Recife, PE, Brasil.

Araújo, A. M. (2003). 0 uso do transporte de pequeno porte por vans como estratégia de redução de emissão de dióxido de carbono (CO2). In S. K. Ribeiro (Coord.) Transporte mais limpo. Rio de Janeiro: COPPE/UFRJ.

Associação Nacional de Transportes Públicos. (2011). Sistemas de informações da mobilidade urbana: relatório geral. Disponível em: http://portal1.antp.net/site/simob/Lists/rltgrl09/rltgrl09menu.aspx

Acesso em outubro 2011.

(c) Labor \& Engenho, Campinas [SP] Brasil, v.10, n.4, p.369-382, out./dez. 2016. 
Banco Mundial. (2002). Cities on the Move: A World Bank Urban Transport Strategy Review. Washington, 2002.

Brasil, Ministério das Cidades. (2005). Estatuto da Mobilidade. Brasília: Secretaria Nacional de Transporte e da Mobilidade Urbana.

Brasil, Ministério das Cidades. (2006). Brasil Acessível. Construindo a cidade. In Programa Brasileiro de Acessibilidade Urbana (v. 2). Brasília: Secretaria Nacional de Transporte e da Mobilidade Urbana.

Brasil, Ministério das Cidades. (2006). Mobilidade e desenvolvimento urbano / Ministério das Cidades, Secretaria de Transporte e da Mobilidade Urbana. Brasília: Ministério das Cidades. (Gestão integrada da mobilidade urbana).

Brasil. (2012). Lei n. 12.587, de janeiro de 2012. Disponível em: <http://www.planalto.gov.br/ccivil_03/ _ato2011-2014/2012/lei/l12587.htm> - Acesso em 05 fevereiro 2012.

Brasileiro, A. F. D. (2002, setembro). Pensando o transporte do futuro [Entrevista concedida a Associação dos Servidores de EMTU - ASSEMTU]. Recife: ASSEMTU.

Bicalho, M. P. (2010, 2ำ quadrimestre). Os desafios da mobilidade urbana para o século XXI. Revista dos Transportes Públicos, Ano 32. [ANTP].

Câmara, P., Braga, M. G. C., \& Santos, R. (2000). A promoção de transporte "ativo": sua relevância e medidas utilizadas em países europeus. Anais do Congresso de Pesquisa e Ensino em Transportes. Gramado, RS, Brasil, 14. [ANPET].

Constituição da República Federativa do Brasil. (1988). Disponível em: <http://www.jusbrasil.com.br/ topicos/1422710/artigo-30-inciso-v-da-constituicao-federal\#topicos-jurisprudencia> - Acesso em 22 outubro 2011.

Dedecca, C. S., Trovão, J. B. M., \& Souza, L. F. (2014, março). Desenvolvimento e equidade. Desafios do crescimento brasileiro. Novos estudos. CEBRAP n. 98 (São Paulo).

Ferraz, A. C. C. P., \& Torres, I. G. E. (2004). Transporte público urbano. São Carlos: Rima.

Francisconi, J. G., \& Souza, M. A. A. (1976). Política nacional de desenvolvimento urbano: estudos e proposições alternativas (Série Estudos para o Planejamento, n. 15). Brasília: IPEA.

Gomide, A. A. (2003, julho). Transporte urbano e inclusão social: elementos para as políticas públicas (Textos para discussão, n. 960). Brasília: IPEA.

Gomide, A. A. (2008). Agenda governamental e o processo de políticas públicas: o projeto de lei de diretrizes da política nacional de mobilidade urbana (Textos para discussão, n. 1334). Brasília: IPEA.

Gondim, M. F. (2011). Transporte não motorizado na legislação urbana no Brasil, Dissertação de Mestrado, Universidade Federal do Rio de Janeiro (COPPE, Programa de Pós-graduação em Engenharia de Transporte). Rio de Janeiro, RJ, Brasil. <http://www.det.ufc.br>

Gottdiener, M. (1997). A produção social do espaço urbano (2a. ed.). São Paulo: Ed. Universitária.

Grande Recife Consórcio de Transportes. Disponível em: <http://www.granderecife.pe.gov.br/ principal.asp > - Acesso em 15 janeiro 2015.

Haefele, E. T. (1973). Transporte e objetivos nacionais (Noel G., Trad.). Rio de Janeiro: Fundação Getúlio Vargas.

Instituto de Pesquisa Econômica Aplicada. (2011). Infraestrutura social e urbana no Brasil: subsídios para uma agenda de pesquisa e formulação de políticas públicas (Série Eixos do Desenvolvimento Brasileiro: A Mobilidade Urbana no Brasil. Comunicados IPEA, n. 94). Brasília, IPEA.

(c) Labor \& Engenho, Campinas [SP] Brasil, v.10, n.4, p.369-382, out./dez. 2016. 
Macário, M. R. M. R. (2003). Integration in urban mobility systems: quality upgrading or competition blockade? Lisboa: Instituto Superior Técnico.

Maia, M. L. A. (2010, junho, 10). A Pós-graduação e o desafio das metrópoles. Brasília: Coordenação de Aperfeiçoamento de Pessoal de Nível Superior (Capes).

Maricato, E. (n. d.). Copa: Paixão, Negócio e Esporte [Vídeo]. Disponível em : <http://www.youtube.com/ watch?v=Ctadh7ehMQo\&feature=related $>-$ Acesso em 16 dezembro 2012.

Lima Neto, O. L. (Org.). (2001). Transportes no Brasil: histórias e reflexões (Empresa Brasileira de Transportes / GEIPOT). Recife: Ed. Universitária da UFPE.

Lima Neto, O. L. (2010, junho). [Entrevista concedida no contexto de uma série de entrevistas feitas com especialistas sobre os problemas ligados a infraestrutura e modais motorizados e não motorizados na RMR]. Jornal Diário de Pernambuco, Caderno Vida Urbana.

Oliven, R. G. (1984). Urbanização e mudança social no Brasil. Petrópolis, RJ: Vozes.

Owen, W. (1971). Caos motorizado (Mário B. P., Trad.). Rio de Janeiro: Bloch.

Pinto, V. P. (2011). Ainda sobre os desafios da mobilidade urbana para 2011. Revista dos Transportes Públicos, Ano 33, 3ํqadrimestre 2010. [ANTP].

Pires, A. B. (2008). A ANTP e os últimos 30 anos de problemas urbanos. Revista dos Transportes Públicos, Ano 30, $1^{\circ}$ trimestre 2008. [ANTP].

Pires, A. B. (2009). Por novos padrões de cidadania e urbanidade. Revista dos transportes públicos. Revista dos Transportes Públicos, Ano 32, $3^{\circ}$ quadrimestre 2009. [ANTP].

Prefeitura da Cidade do Recife. (1979). Lei n. 14110, de 1979. Plano de Desenvolvimento do Recife.

Raia, A. A., Jr. (2000). Acessibilidade e mobilidade na estimativa de um índice de potencial de viagens utilizando redes neurais artificiais e sistemas de informações geográficas. Tese de doutorado, Universidade de São Paulo (EESC-USP), São Carlos, SP, Brasil.

Ribeiro, S. K. et al. (2003). Transporte mais limpo. Rio de Janeiro: Universidade Federal do Rio de Janeiro (COPPE-UFRJ).

Santos, O. A., Jr. (2007). Cidade cidadania e planejamento urbano: perspectiva da reforma urbana. In S. Feldman, \& A. Fernandes (Orgs.). O urbano e o regional no Brasil contemporâneo mutações, tensões e desafios. Salvador: EDUFBA.

Santos, M. (1982). Pensando o espaço do homem. São Paulo: Hucitec.

Santos, M. (1985). Espaço e Método. São Paulo: Nobel.

Santos, M. (1993). A urbanização brasileira. São Paulo: Hucitec.

Santos, M. (1994). Técnica, espaço, tempo: globalização e meio técnico-científico informacional. São Paulo: Hucitec.

Secretaria Nacional de Transporte e Mobilidade Urbana. (2005). Mobilidade. Disponível em: <http:// www.cidades.gov.br/index.php?option=com_content\&view=section\&layout=blog\&id=8\&Itemid=65> Acesso em 02 dezembro 2011.

Silva Filho, N. G. (2010). Os impactos das políticas de transporte na mobilidade urbana: (O caso do Recife). Anais do Simpósio Sergipano de Geografia Contemporânea: recursos naturais, sustentabilidade e apropriação do espaço. Aracaju, SE, Brasil, 1. 
Souza, E. B. de (1992). As políticas federais de desenvolvimento urbano no biênio 1989/1990 (Texto para Discussão, n. 282). Brasília: IPEA.

Vasconcellos, E. A. (2000). Transporte urbano nos países em desenvolvimento: reflexões e propostas. São Paulo: Editoras Unidas.

Vasconcellos, E. A., \& Mendonça, A. (2010). Política Nacional de Transporte Público no Brasil: organização e implantação de corredores de ônibus. Revista dos Transportes Públicos, Ano 33, 3o quadrimestre 2010. [ANTP].

Villaça, F. (1999). Uma contribuição para a história do planejamento urbano no Brasil. In Deak, C., \& Schiffer, S. R. (Orgs.). O processo de urbanização do Brasil. São Paulo: Fupam, Edusp. 